\title{
CHARACTERIZATION OF THE VISCOELASTIC BEHAVIOUR OF GEARS OILS BY EHL SIMULATION
}

\author{
LIONEL SIMO KAMGA ${ }^{1}$, MANUEL OEHLER ${ }^{1}$ AND BERND SAUER ${ }^{1}$ \\ ${ }^{1}$ Technische Universität Kaiserslautern, Department of Mechanical and Process Engineering, inst. of \\ Machine Elements, Gears and Transmissions (MEGT), Gottlieb-Daimler-Straße 42, 67663 \\ Kaiserslautern \\ lionel.skamga@mv.uni-kl.de and http://megt.mv.uni-kl.de
}

Key words: Friction, elastohydrodynamic Simulation, Twin-Disc-Machine, Carreau-Viscosity-Modell

\begin{abstract}
Within the scope of this work, the friction in the lubricating gap between elliptical contact of two surfaces operating under full-film lubrication was experimentally and simulatively investigated. The experimental examination of fluid friction was carried out on a twin-disc-machine by varying the load and slide-to-roll-ratio at constant hydrodynamic velocity and oil inlet temperature. As results, traction curves are obtained which show the change of the coefficient of friction or the shear stress respectively as a function of the slide-to-roll-ratio. From measurements, the maximum shear stress is obtained, which is used for the numerical determination of traction curves. To this end, the EHL theorieis is used, taking into account the pseudoplastic and the viscoelastic behaviour of the lubricant. In this work, two gear oils based on polyalkylene glycol were used as examples of lubricants used in modern worm gearboxes.
\end{abstract}

\section{INTRODUCTION}

In drive technology, the wear of machine components is usually undesirable. The wear can be influenced by introducing a liquid lubricant into the contact zone of the contacting components. When the components are completely separated, the motion resistance is attributed to the internal friction of the shear stressed lubricant. The description of the processes in lubricated contacts is the subject of numerous research activities based on elastohydrodynamic Lubrication (EHL). Summaries of the development of research in this field can be found, for example, in the work of Leeuwen and Schouten [1] and Spikes [2].

The depth of detail in EHL simulation ranges from isothermal considerations for smooth surfaces [3] to the consideration of thermal influences and rough surfaces [4] as well as approaches to mass-conserving cavitation [5]. Indispensable for a reliable simulation of friction in EHL contact is a detailed description of the rheology of the lubricant. This includes the dependence of density and dynamic viscosity on pressure and temperature as well as the shear rate dependence of the dynamic viscosity in loaded contact. The shear rate dependence of the dynamic viscosity can be described for pseudoplastic fluids (viscosity decreases with increasing shear rate) for example by the approaches of Eyring [6], Bair and Winer [7] or Carreau [8]. Bair summarizes in [9] some models for the description and experimental determination of essential rheological properties. In [10], experimental results from different tribometer experiments are used to characterize the shear rate dependence of the dynamic viscosity as input data for the EHL simulation. Different lubricants were investigated and approximate solutions were presented to describe 
the phenomenon. Input data for the EHL simulation can be obtained from measurements on componentrelated functional test rigs such as the Twin-Disc-Machine and ball-on-disc tribometer (Mini-TractionMachine, MTM). This is shown by Meyer [11], Strubel [12] and Fruth [13].

The aim of this work is the development of an EHL simulation model to determine the friction in an elliptical point contact between two bodies of steel and bronze under isothermal lubrication conditions. In addition to the pseudoplastic behaviour, the viscoelastic behaviour of the lubricant and a mass-conserving cavitation algorithm according to Elrod [5] are taken into account. The results of the considerations are traction curves for the polyalkylene glycol (PAG) based oil, which describe the relationship between the slide-to-roll-ratio $S R R$ and the coefficient of friction $\mu$ in the lubricated contact. Necessary for the simulative calculation of the friction is the experimental determination of the maximum shear stress of the lubricant, which is obtained by model tests on the Twin-Disc-Machine. The presented method allows the characterization of the pseudoplastic behaviour of fluids independent of approximate solutions for the critical or limit shear stress, which are described in the literature [10].

\section{NUMERICAL INVESTIGATION OF TRACTION CURVES}

\subsection{Mathematical description of the EHL theory}

The numerical investigation of traction curves is based on the elastohydrodynamic lubrication (EHL) theory. The EHL represents the hydrodynamic type of lubrication in which contacting bodies elastically deform due to the hydrodynamic pressure built up in the lubricating gap.

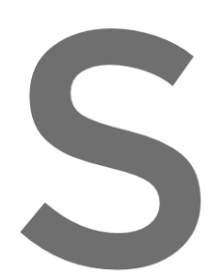

For the mathematical de

depicts the dependence

and $u_{2}$ of the contacting

(density $p$ and viscosity

pressure at the output of th

according to Jakobsson, Floberg and Olson (JFO)
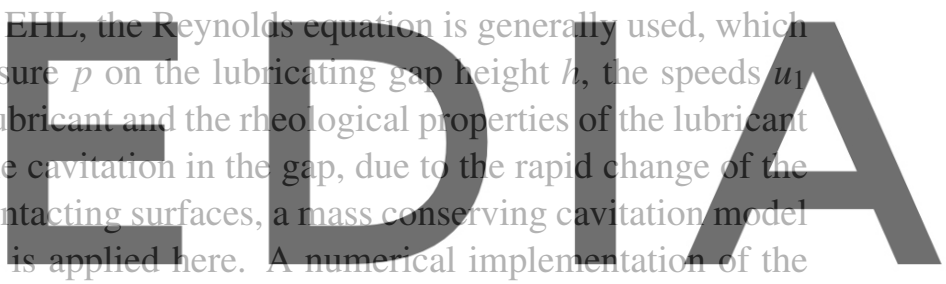

JFO model was presented by Elrod [5], who introduces a gap filling factor $\vartheta$ as a solution variable at the

Register forfficel (aitahttps//www.scipedia.com to download the version without the watermark

This paper takes in consideration the effects of surfaces roughness on the fluid flow in the gap between the contacting bodies. For this purpose, the indirect method based on fiow factors and presented by Morales-Espejel [15] is used.

The generalized stationary Reynolds equation (1) for calculating the pressure distribution and the gap height of lubricated contacts is defined as

$$
\begin{array}{r}
\frac{\partial}{\partial x}\left(\phi_{x}^{p} \cdot \rho \cdot F_{2} \cdot \frac{\partial p}{\partial x}\right)+\frac{\partial}{\partial y}\left(\phi_{y}^{p} \cdot \rho \cdot F_{2} \cdot \frac{\partial p}{\partial y}\right)= \\
u_{m} \cdot \frac{\partial}{\partial x}(\rho \cdot h \cdot(1-\vartheta))+\frac{u_{r}}{2} \cdot \frac{\partial}{\partial x}\left[\rho \cdot(1-\vartheta)\left(h-2 \cdot \frac{F_{1}}{F_{0}}\right)\right]+\frac{u_{r}}{2} \cdot \sigma \cdot \frac{\partial}{\partial x}\left(\rho \cdot \phi_{x}^{s} \cdot(1-\vartheta)\right)
\end{array}
$$

$F_{0}, F_{1}$ and $F_{2}$ are the Dowson integral functions [16] defined as

$$
F_{0}=\int_{0}^{h} \frac{1}{\eta^{*}} d z \quad F_{1}=\int_{0}^{h} \frac{z}{\eta^{*}} d z \quad F_{2}=\int_{0}^{h} \frac{z}{\eta^{*}}\left(z-\frac{F_{1}}{F_{0}}\right) d z
$$


$\eta^{*}$ describes the effective dynamic viscosity of the lubricant, $\vartheta$ the gap fill factor, $\phi^{\mathrm{p}}$ the pressure flow factor, $\phi^{\mathrm{s}}$ the shear flow factor and $u_{\mathrm{m}}$ and $u_{\mathrm{r}}$ respectively the hydrodynamic mean velocity and the relative velocity of the contacting surfaces. $\sigma$ is the combined surface roughness. $x$ and $y$ describe respectively the direction of flow of the lubricant and the direction perpendicular to it.

The gap height $h$, which results from the deformation of the contacting surfaces due to the hydrodynamic pressure is calculated using

$$
h(x, y)=h_{0}+\frac{x^{2}}{2 \cdot R_{x}}+\frac{y^{2}}{2 \cdot R_{y}}+\frac{2}{\pi \cdot E^{\prime}} \cdot \iint_{\Omega} \frac{p\left(x^{\prime}, y^{\prime}\right) d x^{\prime} d y^{\prime}}{\left(x-x^{\prime}\right)^{2}+\left(y-y^{\prime}\right)^{2}}
$$

whereby $R_{x}$ and $R_{y}$ describes the curvature radius of the contacting bodies respectively in the $x$ and $y$ direction. The fourth term in (3) describes the Boussinesq equation, which is used here to determine the deformation of the contacting bodies in the calculation domain $\Omega$ [14].

\subsection{Rheology of the lubricant}

To solve the Reynolds equation (1), knowledge of the density and viscosity of the lubricant is required. Since the temperature influence was neglected in this work, the calculation of the pressure dependent density was carried out according to the widely used Dowson and Higginson equation (4). The pressure and shear rate dependence of the viscosity of the lubricant were respectively determined using the Modul or Peeken equation (5) and the Carreau viscosity model [8]. The Carreau equation is shown in (6).
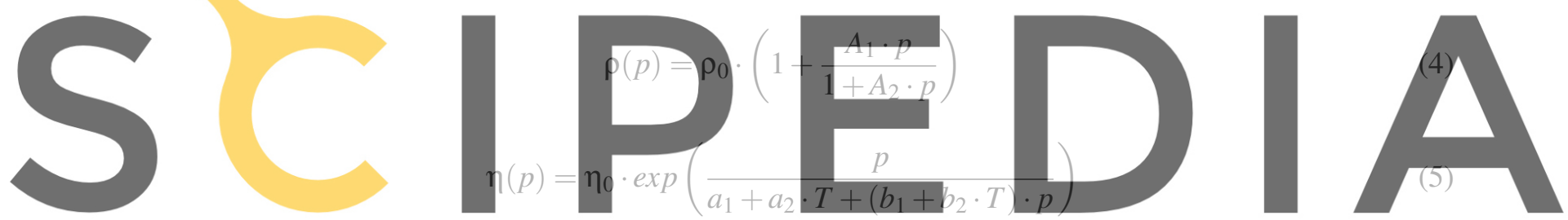

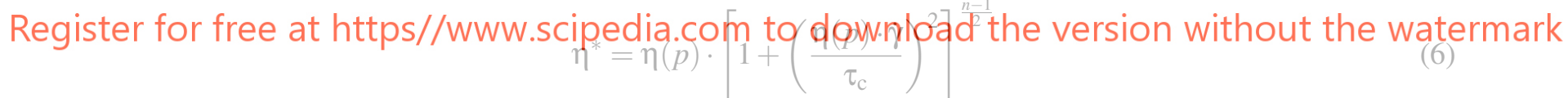

$\eta$ represents the pressure dependent viscosity at low shear rates, $\dot{\gamma}=\sqrt{\dot{\gamma}_{x}^{2}+\dot{\gamma}_{y}^{2}}$ the shear rate in the fluid and $\tau_{\mathrm{c}}$ the critical shear stress of the lubricant, from which the lubricant behaves non-Newtonian.

Since in EHL lubricant films, fluid elements are exposed to a shear force that depends on the shear rate (viscosity) and the elastic shear (elasticity) built up over the course of the shear process, the viscoelastic behaviour of the lubricant is taken into account here using the classical Maxwell model [17] described by equation (7), where $\tau$ describes the shear stress and $G \approx 4 \cdot \tau_{\mathrm{L}}$ the elastic shear modulus of the lubricant according to Dyson [18]. $\tau_{\mathrm{L}}$ is the maximaum shear stress that the fluid can achieve and can be determined experimentally. Table 1 summarizes the parameters used in the modul equation (5) for the considered lubricants in this work.

$$
\dot{\gamma}=\frac{\tau}{\eta^{*}}+\frac{1}{G} \cdot \frac{d \tau}{d t}
$$


Table 1: Parameters of the modul equations for the investigated lubricants based upon data from high pressure viscometry

\begin{tabular}{ccccc}
\hline Oil type & $a_{1} / \mathrm{Pa}$ & $a_{2} / \mathrm{Pa} \cdot{ }^{\circ} \mathrm{C}^{-1}$ & $b_{1} /-$ & $b_{2} /{ }^{\circ} \mathrm{C}^{-1}$ \\
\hline PAG 150 & $4.1404 \cdot 10^{7}$ & $5.4836 \cdot 10^{5}$ & 0.0927 & $-2.6542 \cdot 10^{-4}$ \\
\hline PAG 680 & $8.2488 \cdot 10^{7}$ & $7.6768 \cdot 10^{5}$ & 0.1237 & $-1.2530 \cdot 10^{-4}$
\end{tabular}

\subsection{Solution technique}

Before the numerical calculation, the equations described above were nondimensionalized according to [19]. For the subsequent discretization of the dimensionless equations, the finite volume method was used, whereby for the right hand side of the Reynolds equation an first order upstream backward method was used [20]. The calculation domain was discretized using a rectangular grid of constant mesh size $\Delta X$ and $\Delta Y$ in both the $x$ and $y$ direction and $\Delta Z$ in the $z$ direction. The size of the mesh used was $128 \mathrm{X}$ 128 X 11. Figure 1 shows the flow chart used in this work to determine the fluid friction coefficient in the gap of the contacting surfaces for a external applied load.
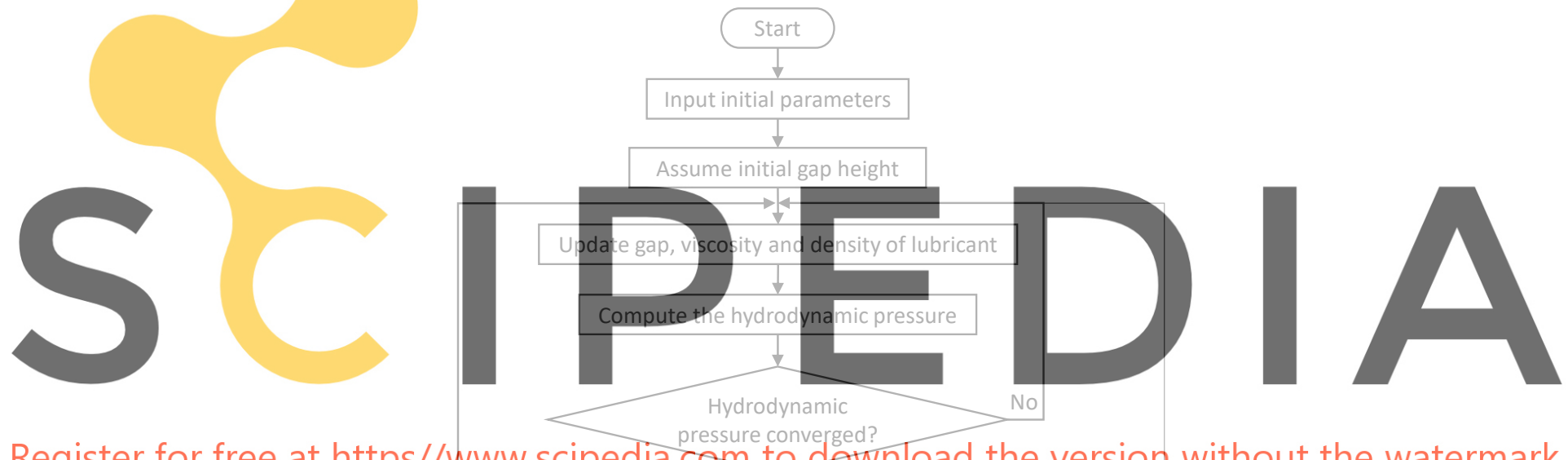

Register for free at https//www.scipedia.com to download the version without the watermark

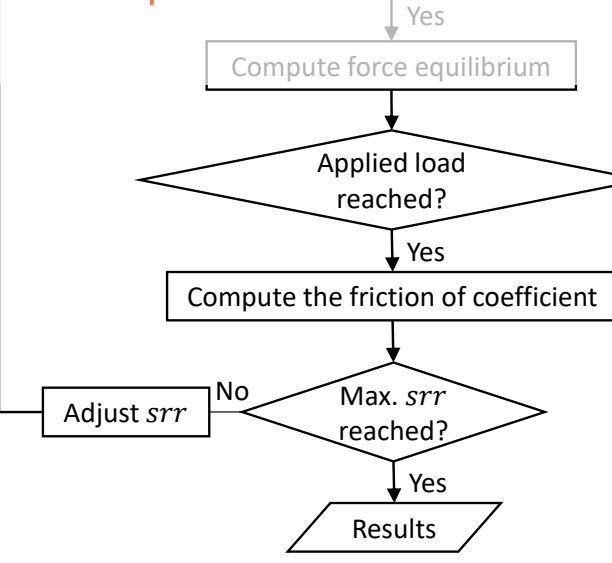

Figure 1: Flow chart of the simulation

After initialization of the contact parameters (e.g. load, velocity, inlet temperature), the hydrodynamic 
pressure distribution is determined in the inner loop iteratively using the Reynolds equation (1) for a given gap height, fluid density and viscosity distribution. For this purpose, the solution algorithm based on the Fischer-Burmeister-Newton method [21] was used. For a converged solution of the hydrodynamic pressure, the equilibrium of forces beetwen the external applied load and the load in the gap due to the hydrodynamic pressure is checked in the next loop. This is carried out using equation (8), The inner loop using to calculate the hydrodynamic pressure is repeated until the residue of load equilibrium equation and the relative error in pressure distribution is less than the discretization's error.

$$
\iint_{\Omega} p d x d y=F_{\mathrm{N}}
$$

In order to calculate the friction in the fluid, equation (9) is used. The calculation of the shear stress $\tau$ in the lubricating gap under viscoelastic behaviour of the lubricant is described in [17].

$$
\mu=\frac{F_{\mathrm{R}}}{F_{\mathrm{N}}}=\frac{\iint \tau d x d y}{\iint p d x d y}
$$

\subsection{Results}

In this work, the contact between a steel disc with a Young's modulus of $E_{1}=210 \mathrm{GPa}$ and a bronze disc with a Young's modulus of $E_{2}=98.1 \mathrm{GPa}$ was investigated, whereby the bronze disc was manufactured cylindrical and the steel disc slightly convex. The examined lubricants were injected into the contact at

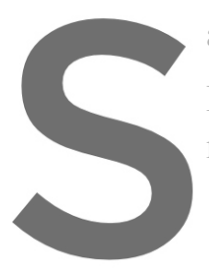
a temperature of $40^{\circ} \mathrm{C}$

In Figure 2, the EHL's mean Hertzian pressure o
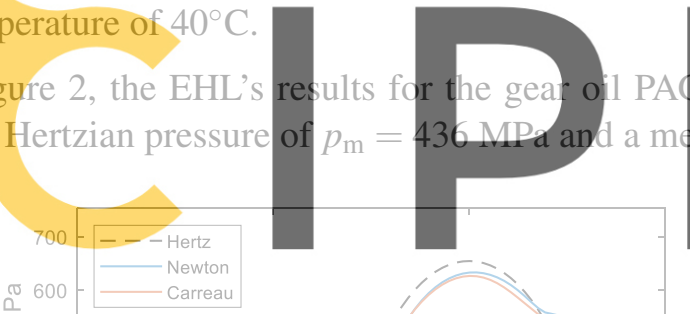

Register for frę eart https//www.sćipedia.com to
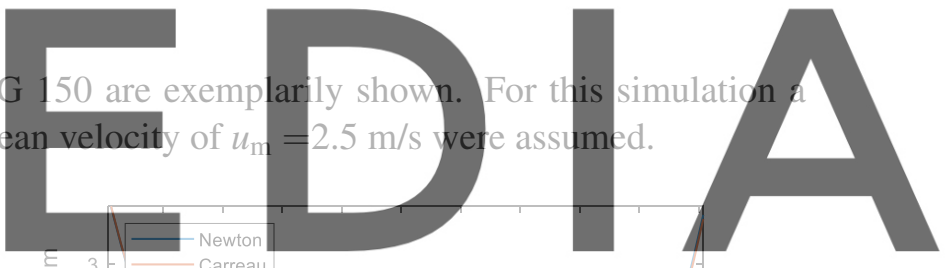

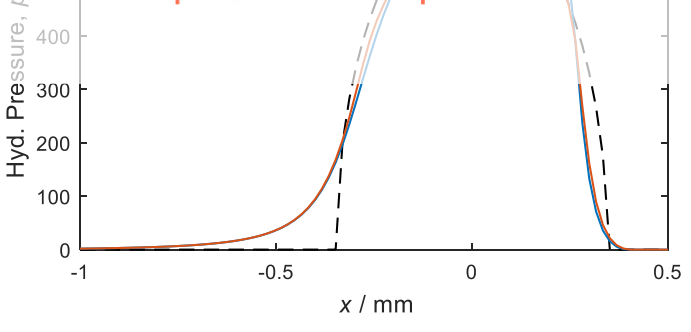

(a)

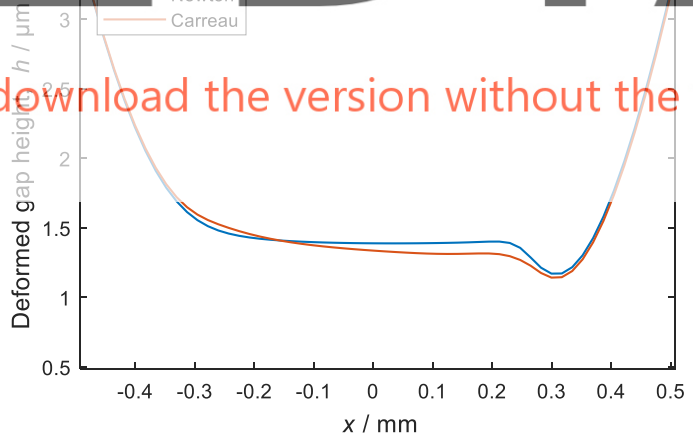

(b)

Figure 2: (a) Numerical solution of the pressure distribution along the y-axis according to the Carreau and Newton viscosity model. (b) Numerical solution of the gap height along the y-axis according to the Carreau and Newton viscosity model.

Figure 2 show respectively the comparison of the pressure and gap height profiles between the contacting surfaces using the Newtonian and Carreau viscosity models. In this simulation, the slide-to-roll ratio is 
assumed to be $30 \%$. A critical shear stress of $\tau_{\mathrm{c}}=4 \mathrm{MPa}$ and a power-law-index of $n=0.35$ are assumed. For both the Newtonian and the Carreau model, the solutions contain all characteristic aspects of the solution of an EHL point contact problem. The pressure ressembles the Hertzian semi-elliptical pressure, which shows an gradual increase in the inlet and a rapid drop to the cavitation pressure in the outlet. Due to the exponential viscosity-pressure equation, a pressure spike occurs just before the cavited region. The magnitude of the pressure spike for the Carreau model is smaller than that for the Newtonian model due to the pseudoplastic effect, which lead to a lower effective viscosity. Due to the elastic deformation of the contacting bodies, the surface is flattened in the centre of the contact region, whereby the gap height for the Carreau model is predicted to be smaller than that for the Newtonian model.

\section{MEASUREMENTS OF TRACTION CURVES AND COMPARISON WITH SIMULATION}

For the experimental evaluation of traction curves, measurements were carried out on the MEGT's TwinDisc-Machine, which is described in [23]. The experimental setup is shown in figure 3.

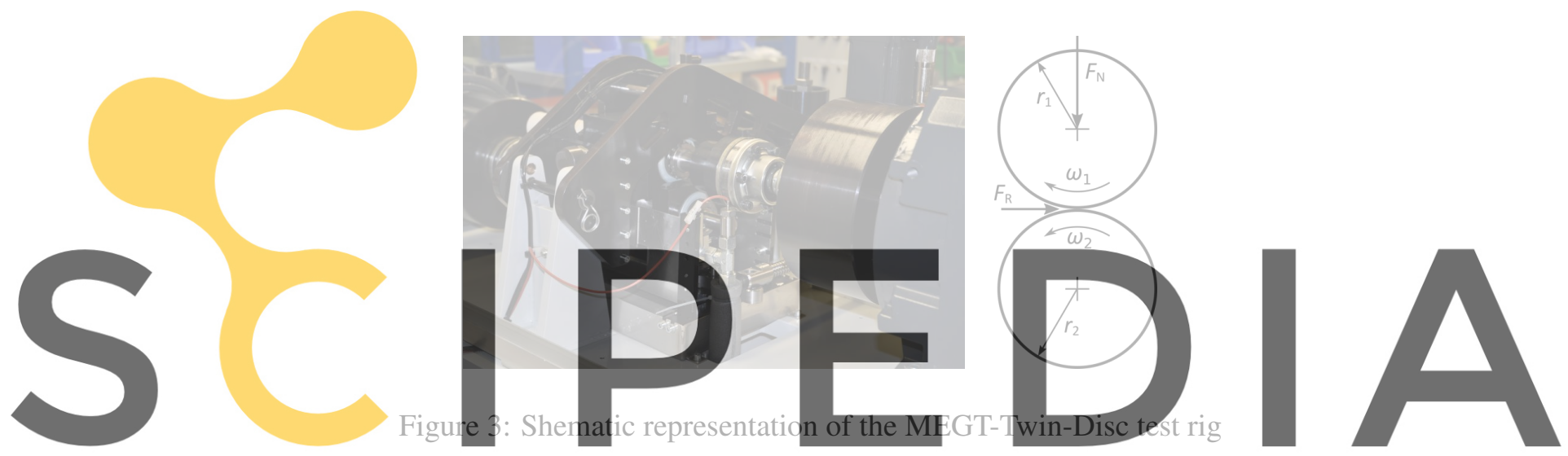

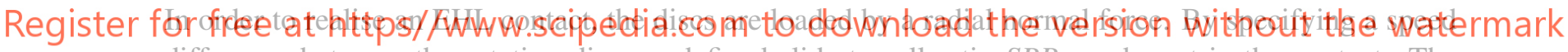
difference between the rotating discs, a defined slide-to-roll ratio SRR can be set in the contact. The application of the friction coefficient $\mu$ over the slide-to-roll ratio SRR results in the traction curve. The coefficient of friction can be determined by the ratio of the measured friction force $F_{\mathrm{R}}$ to the normal force $F_{\mathrm{N}}$. The lubrication condition in the contact is generally determined by the dimensionless specific film thickness $\lambda=h / \sigma . h$ describes the central gap height according to Hamrock and Dowson [22] and $\sigma$ the standard deviation of the combined roughness profile of the two contact bodies. It is generally assumed that fluid friction regime occurs at $\lambda \geq 3$ [14].

Figures 4 show the comparison between the simulated and measured coefficients of friction for the examined lubricants. The comparison of the measured and calculated traction curves shows that they have the same course, whereby a linear course is observed in the low range of the slide-to-roll ratio and a degressive course from a certain value upward. The linear course of the traction curves represent the Newtonian flow and the degressive increase the pseudoplastic flow behaviour of the lubricant.

The calculated and measured traction curves for the lubricant PAG 680 show a good congruence over a wide range of the slide-to-roll ratio. Due to the fact that the oil PAG 150 has a relatively lower viscosity than the PAG 680, a smaller film thickness is formed in the contact zone and the shear rate become there- 


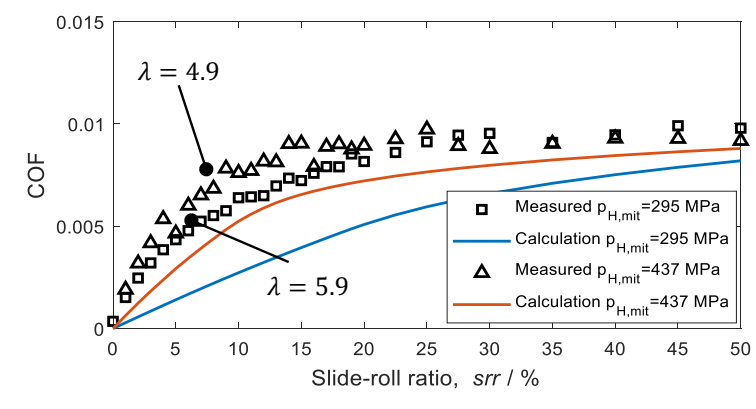

(a)

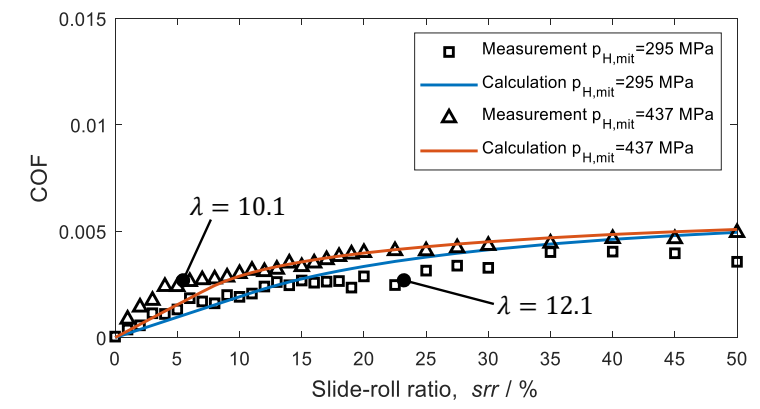

(b)

Figure 4: (a) Measured and simulated traction curves for the oil PAG 150. (b) Measured and simulated traction curves for the oil PAG 680, at different Hertzian mean pressures

fore higher. This could explain the higher coefficient of friction for the lubricant with lower viscosity. For these results a critical shear stress $\left(\tau_{c}\right)$ of $4 \mathrm{MPa}$ and $3 \mathrm{MPa}$ was considered, respectively for the lubricants PAG 150 and PAG 680. The Carreau exponent $n$ was 0.35 and 0.4 respectively for the oils PAG 150 and PAG 680.

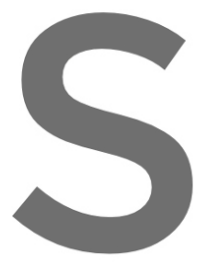

CONCLUSIONS

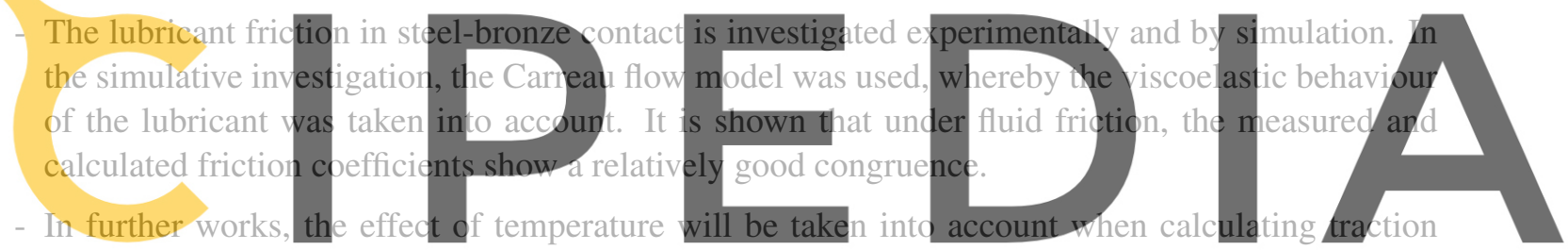

curves. In addition, the calculation model will be extended to include mixed friction conditions in

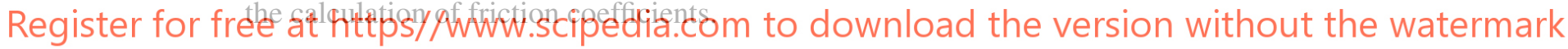

REFERENCES

[1] Schouten, J.W. and van Leeuwen, H. Die Elastohydrodynamik, Geschichte und Neuentwicklungen. McGraw Hill, (1995).

[2] Spikes, H. Sixty years of EHL.Lubr. Sci. (2006) 18:265-291.

[3] Hamrock, B.J. and Dowson, D.D. Isothermal elastohydrodynamic lubrication of point contacts: part 1-theoretical formulation.ASME J. Lubr. Tech. (1976) 98(2):223-228.

[4] Solovyev, S. Reibungs- und Temperaturberechnung an Festkörper- und Mischreibungskontakten. Otto-von-Guericke-Universität, Magdeburg (2007).

[5] Elrod, H.G. A cavitation algorithm. J Lubr Technol (2007) 103(3):350-354.

[6] Eyring, H. Viscosity, plasticity, and diffusion as examples of absolute reaction rates. J. Chem. Phys. (1936) 4:283-291.

[7] Bair, S. and Winer, W.O. A rheological model for elastohydrodynamic contacts based on primary 
laboratory data. J Lubr. Technol. (1979) 101(3):258-265.

[8] Carreau, P.J. Rheological Equations from Molecular Network Theories. Trans. of the Socie. of Rheo. (1972) 1:99-127.

[9] Bair, S. High pressure rheology for quantitative elastohydrodynamics.. Elsevier, Oxford, (2007).

[10] Beilicke, R.; Bader, N. and Brouwer, L. Tribologische Fluidmodelle für Nebenantriebsaggregate in Hybrid-und Elektrofahrzeugen, Abschlussbericht zum FVV-Vorhaben Nr. 1138 (Heft 1092). Forschungsvereinigung Verbrennungskraftmaschinen e. V., Frankfurt/Main (2016)

[11] Meyer, C. Reibung in hoch belasteten EHD-Wälzkontakten. Leibniz Universität, Hannover (Dissertation) (2010).

[12] Strubel, V.; Fillot, N; Ville, F.;Cavoret, J.; Vergne, P.; Mondelin, A. and Maheo, Y. Particle entrapment in hybrid lubricated point contacts. Trib. Trans. (2016) 59(4):768-779.

[13] Fruth, T. Vom tribologischen Modellversuch zum Maschinenelement: Berücksichtigung des rheologischen Verhaltens von Schmierstoffen in der Wälzlagersimulation. Technische Universität, Kaiserslautern (Dissertation) (2018).

[14] Bartel, D. Simulation von Tribosystemen, Grundlage und Anwendung. Vieweg+Teubner, Wiesbaden, (2010).

[15] Morales-Espejel, G.E. Flow factors for non-Gaussian roughness in hydrodynamic lubrication: An analytical interpolation. Proc. of the Instit. of Mech. Eng., Part C: J. of Mech. Eng. Scie. (2009)

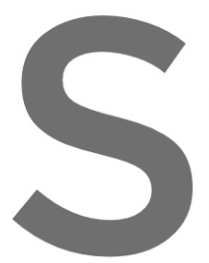
223(6): 1433-144

[16] Dowson, D. A generalized 1 4(2):159-170.

[17] Wang, D. Berechnung der Wälzlagerreibung a elle. Leibniz Universität, Hannover (Dissertation

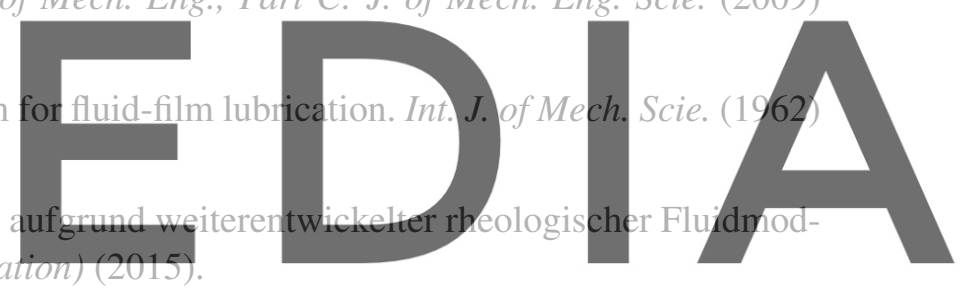

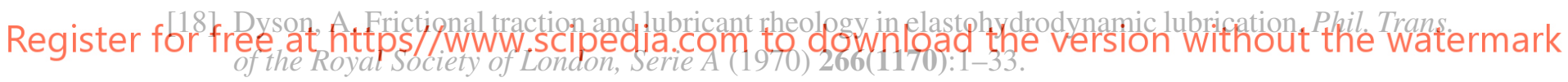

[19] Venner, C.H. and Lubrecht, A.A. Multi-Level methods in lubrication. Elsevier, (2000).

[20] Mazumder, S. Numerical methods for partial differential equations. Finite difference and finite volume methods. Elsevier AP, (2016).

[21] Woloszynski, T.; Posiadlo, P. and Stachowiak, G.W. Efficient solution to the cavitation problem in hydrodynamic lubrication. Tribology Letters (2015) 58(1).

[22] Hamrock, B.J. and Dowson, D. Isothermal Elastohydrodynamic lubrication of point contacts - Part III - fully flooded results. Trans. of the ASME, Series F (1977) 2(99):264-275.

[23] Simo Kamga, L., Oehler, M., Magyar, B. and Sauer, B. Charakterisierung des strukturviskosen Verhaltens von Schmierstoffen durch Kombination von Experiment und EHD-Simulation mithilfe des Carreau-Modells. Forschung im Ingenieurwesen (2018) 82:301-309. 